(C) 1996 IEEE. Personal use of this material is permitted. However, permission to reprint/republish this material

for advertising or promotional purposes or for creating new collective works for resale or redistribution to servers

or lists, or to reuse any copyrighted component of this work in other works must be obtained from the IEEE.

\title{
THE FERMI FEL PROJECT AT TRIESTE
}

D. Bulfone, F. Cargnello, G. D'Auria, F. Daclon, M. Ferianis, M. Giannini,

G. Margaritondo§, A. Massarotti, A. Rindi, R. Rosei, C. Rubbia¥, R. Visintini,

R.P. Walker ${ }^{\dagger}$, A. Wrulich, D. Zangrando, Sincrotrone Trieste S.c.p.A.

F. Ciocci, G. Dattoli, A. De Angelis Il, A. Dipace, A. Doria, G. P. Gallerano, F. Garosi, L. Giannessi,

E. Giovenale, L. Mezi, P. L. Ottaviani, A. Renieri, E. Sabia, A. Segreto $\$$, A. Torre, ENEA-Frascati

M. Castellano, P. Patteri, S. Tazzari, F. Tazzioli, INFN-Frascati

F. Cevenini, INFN-Naples and Univ. Naples, Dept. of Physics

A. Cutolo, Univ. Naples, Dept. of Electronic Engineering

$\dagger$ corresponding author; II guest; $\ddagger$ study grant holder

$\S$ also at EPFL, Lausanne, Switzerland; ¥ also at CERN, Geneva, Switzerland

The main features of the FERMI project are described, including beam transport design and FEL performance calculations.

\section{INTRODUCTION}

The FERMI (Free Electron Radiation and Matching Instrumentation) project aims to construct an Infra-Red FEL user facility covering a broad spectral range $(2-250 \mu \mathrm{m})$ to complement the high brightness radiation from the ELETTRA synchrotron radiation facility at Trieste [1]. A unique feature of the project will be the possibility of carrying out "pumpprobe" experiments using synchronized radiation beams from FERMI and ELETTRA on the same sample.

The project was launched at a meeting of Italian FEL experts held in Trieste on the 18th November 1994, chaired by C. Rubbia, as a collaboration between Sincrotrone Trieste, ENEA (Frascati), INFN (Frascati) and the University of Naples (Department of Electronic Engineering).

The facility will make use of an existing linac, that forms part of the ELETTRA injection system, and a hall into which the beam can be extracted. In addition, for the first phase of the project equipment will be used from the suspended INFN/ENEA "SURF" FEL experiment [2], including the undulator, beam transport magnets and optical cavity.
Development of the facility is foreseen in three phases. Phase 1 will consist of setting up the first FEL (FEL-1) to cover the range 5-20 $\mu \mathrm{m}$. Initially, the existing optical cavity will be used to demonstrate laser operation at a fixed wavelength of $16 \mu \mathrm{m}$. Later, new mirrors will be installed allowing tuneability over the range $5-20 \mu \mathrm{m}$ with a higher output coupling, permitting a first user experiment to be carried out. In Phase 2 a second FEL (FEL-2) will be set up for the $15-250 \mu \mathrm{m}$ region. To allow a full support for user experiments a new building will be constructed (Phase 3) hosting several experimental stations. As part of this phase a new linac gun will also be implemented to reduce the emittance, which is necessary to reach the shortest wavelengths on FEL-1 (2-5 $\mu \mathrm{m})$.

\section{LAYOUT}

Figure 1 shows the layout of the facility adjacent to the ELETTRA storage ring. The beam from the first $100 \mathrm{MeV}$ part of the $1.5 \mathrm{GeV}$ injector linac will be transported into an existing hall adjacent to the linac tunnel, sufficiently large (32 $\mathrm{m} \times 10 \mathrm{~m})$ to accommodate both FELs as well as space for power supplies etc. and an area for optical diagnostics and pilot experiments. In the final phase the FEL beams will be

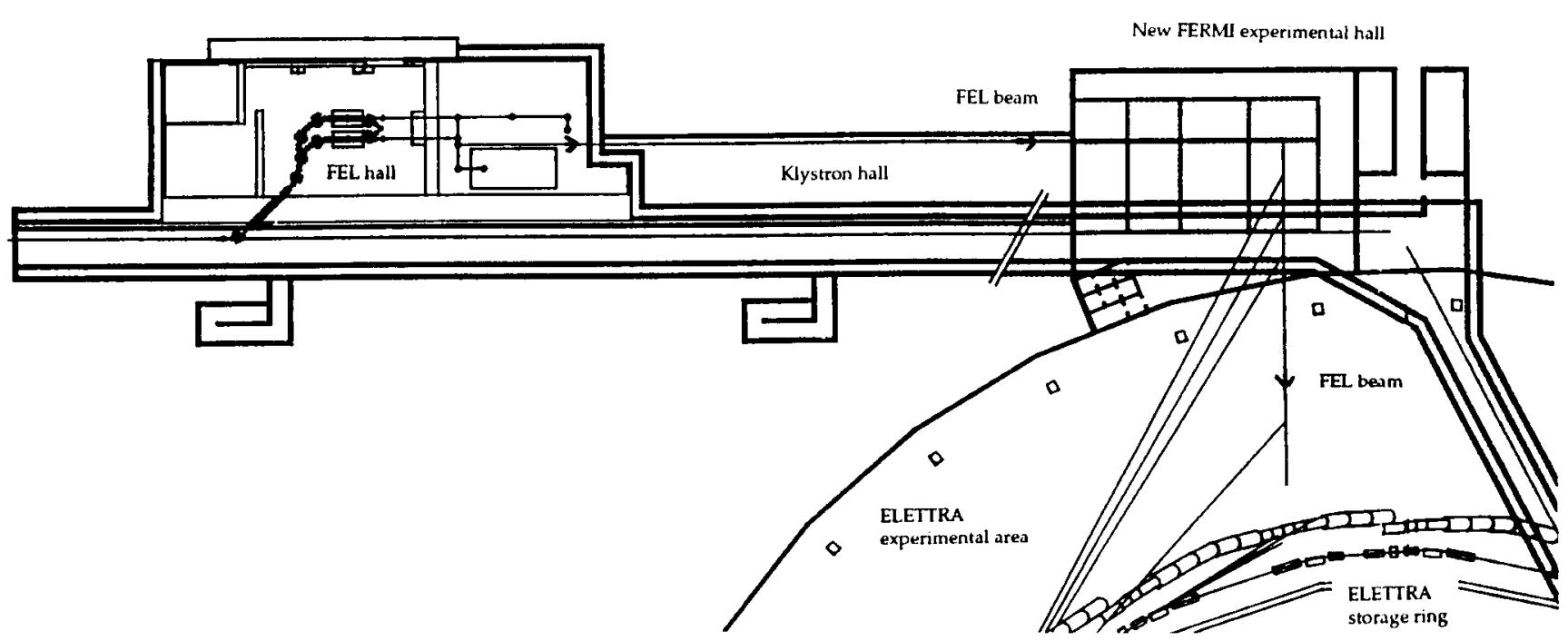

Fig. 1 Layout of the FERMI FEL facility. 
transported along the klystron gallery (above the linac tunnel) and into a new FEL experimental area $(\sim 21 \mathrm{~m} \mathrm{x} 17 \mathrm{~m})$ which will host a number of experimental hutches. The location of the new building will allow the possibility of easily transporting synchrotron radiation beams into the FEL experimental area, or FEL radiation into the ELETTRA experimental hall.

\section{LINAC}

The low energy part of the linac has been designed to operate in a FEL mode in the $20-75 \mathrm{MeV}$ range with a $10 \mu \mathrm{s}$ pulse length. First tests in this mode of operation are reported elsewhere in these Proceedings [3]. Table 1 summarises the expected linac parameters, on which the FEL performance calculations were based. It will be seen that the linac performance is not sufficient to allow saturation to be reached below about $5 \mu \mathrm{m}$, and therefore possible schemes for upgrading the gun are being evaluated.

Table 1. Main linac parameters in the FEL-mode

\begin{tabular}{|l|l|}
\hline Energy, $\mathrm{MeV}$ & $20-75$ \\
\hline Macropulse repetition rate, $\mathrm{Hz}$ & 10 \\
\hline Macropulse length, $\mu \mathrm{s}$ & 10 \\
\hline Charge per micropulse, $\mathrm{nC}$ & 0.4 \\
\hline Micropulse length (FWHM), ps & 10 \\
\hline Peak current, A & 37.5 \\
\hline Micropulse repetition rate, $\mathrm{MHz}$ & $20.8-31.3$ \\
\hline Normalized emittance (rms), mm mrad & 62.5 \\
\hline Energy spread at $75 \mathrm{MeV}, \%$ & \pm 0.3 \\
\hline
\end{tabular}

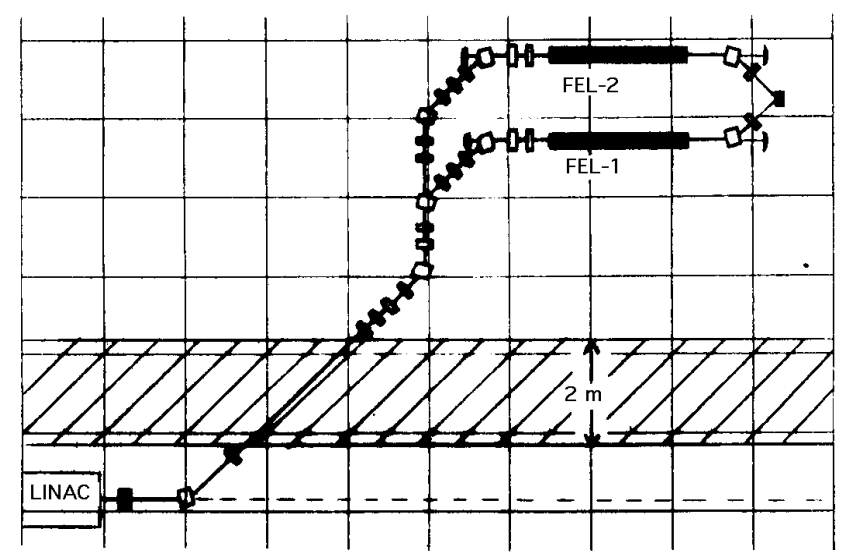

Fig. 2 Layout of the transport line and two FELs

\section{BEAM TRANSPORT}

A particular requirement of the transport line is to provide a variable path length dependence with energy, in order to maintain high peak currents or to allow bunch length manipulations in conjunction with linac phase adjustments. Fig. 2 shows a suitably flexible design using four bends for each FEL line. Fig. 3 shows the optical functions for FEL-1 in the isochronous case. The design is compatible with operation over the full 20-75 MeV range using the existing magnets.
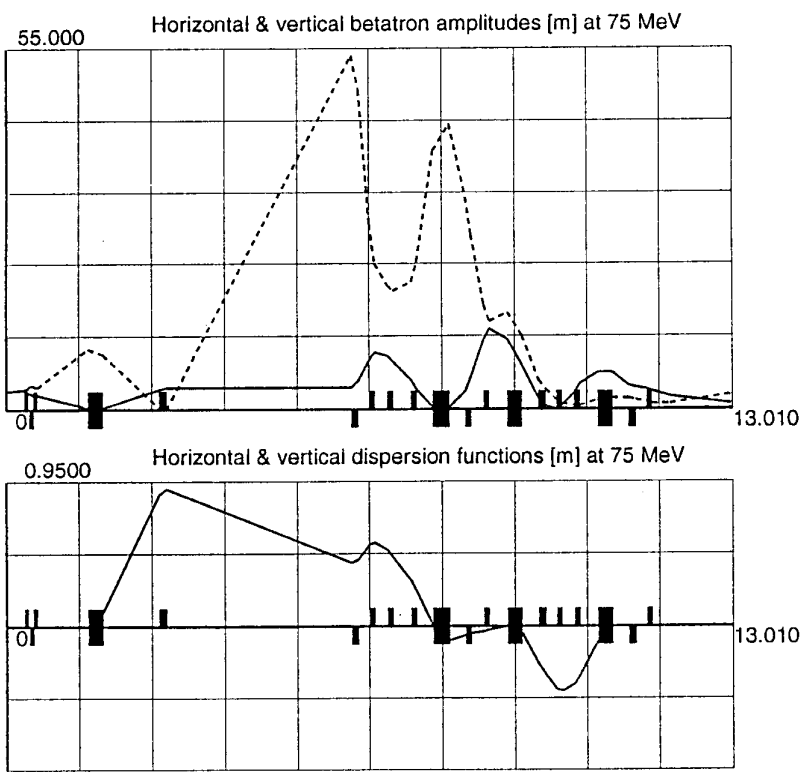

Fig. 3 FEL-1 transport line optics in the isochronous case.

\section{UNDULATORS AND OPTICAL CAVITIES}

Table 2 summarises the undulator parameters. The undulator for FEL-1 was built by Ansaldo in collaboration with ENEA, Frascati [4]. The minimum gap of $20 \mathrm{~mm}$ allows a vacuum aperture of $15 \mathrm{~mm}$ which gives minimal diffraction losses at $20 \mu \mathrm{m}$. The FEL-2 undulator is designed to have the shortest period allowing $250 \mu \mathrm{m}$ to be reached at the lowest envisaged energy of $20 \mathrm{MeV}$, compatible with a vacuum aperture of $40 \mathrm{~mm}$ for minimal diffraction losses.

Table 2. Main parameters of the FEL undulators.

\begin{tabular}{|l|l|l|}
\hline & FEL-1 & FEL-2 \\
\hline Length, $\mathrm{m}$ & 2.20 & 2.28 \\
\hline Period, $\mathrm{m}$ & 0.044 & 0.095 \\
\hline Number of periods & 50 & 24 \\
\hline Minimum gap, mm & 20 & 45 \\
\hline Peak field, T & 0.35 & 0.43 \\
\hline K parameter, max. & 1.44 & 3.79 \\
\hline
\end{tabular}

The optical cavity length has been chosen to be $5.4 \mathrm{~m}$, which allows the same bunch separation to be obtained in ELETTRA with a regular filling pattern with 24 bunches. For FEL-1 the mirror adjustment system for the SURF project will be used which has combined PZT and motorized adjustment of mirror tilt and longitudinal position [5]. Mirrors are available for the first demonstration experiment at $16 \mu \mathrm{m}$. Thereafter other mirrors will be substituted to cover the $5-20 \mu \mathrm{m}$ range. No decision has yet been taken about the FEL-2 optical cavity that could employ metal mesh mirrors and a waveguide cavity. 
VI. PERFORMANCE CALCULATIONS
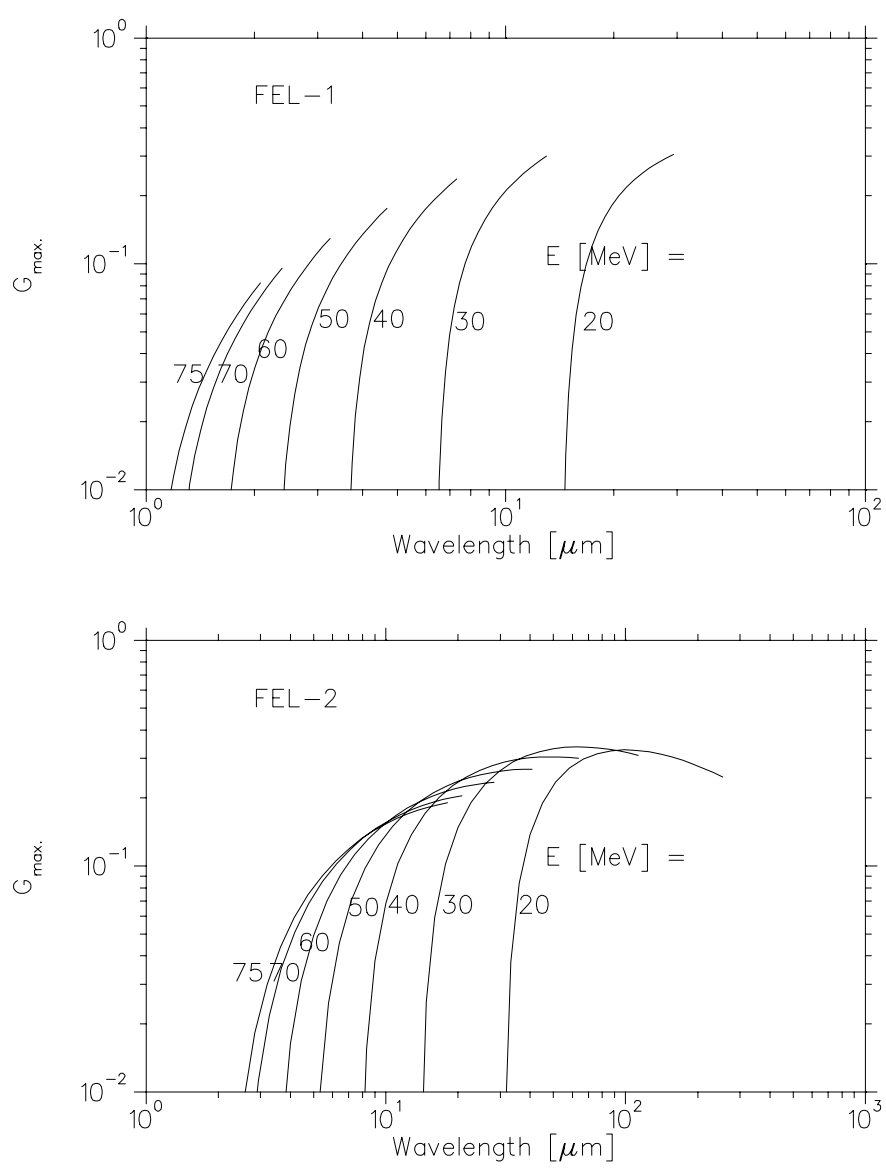

Fig. 4. Small signal gain for FEL-1 and FEL-2.

The estimated small signal gain $\left(\mathrm{G}_{\max }\right)$, including the effects of emittance, energy spread and slippage is shown in fig. 4 as a function of undulator $\mathrm{K}$ value for various electron beam energies. Table 3 presents a summary of the optimized parameters at various wavelengths, assuming $5 \%$ output coupling and $1 \%$ losses. It can be seen that the gain is sufficient above about $5 \mu \mathrm{m}$ to reach saturation in a sufficiently small time $\left(\tau_{\mathrm{r}}\right)$ with respect to the macropulse duration. The results indicate that high micropulse energies ( $\left.\mathrm{E}_{\text {micro. }}\right)$ and power $\left(\mathrm{P}_{\text {micro. }}\right)$ can be produced, with low average power $\left(\mathrm{P}_{\mathrm{av}}\right)$ due to the low duty cycle.

Table 3. Results of FEL performance calculations.

\begin{tabular}{|l|l|l|l|l|l|l|l|l|}
\hline & \multicolumn{4}{|c|}{ FEL-1 } & \multicolumn{4}{c|}{ FEL-2 } \\
\hline$\lambda, \mu \mathrm{m}$ & 5 & 10 & 16 & 20 & 20 & 50 & 100 & 250 \\
\hline $\mathrm{E}, \mathrm{MeV}$ & 48 & 34 & 27 & 24 & 46 & 30 & 23 & 20 \\
\hline $\mathrm{G}_{\max .}(\%)$ & 18.3 & 27.3 & 31.2 & 31.4 & 24.0 & 33.1 & 33.6 & 25.0 \\
\hline$\tau_{\mathrm{r}}, \mu \mathrm{s}$ & 6.3 & 3.8 & 3.2 & 3.2 & 4.3 & 3.0 & 2.9 & 4.1 \\
\hline $\mathrm{E}_{\text {micro }}, \mu \mathrm{J}$ & 27 & 24 & 20 & 18 & 96 & 62 & 40 & 23 \\
\hline $\mathrm{P}_{\text {micro, }}, \mathrm{MW}$ & 2.2 & 2.0 & 1.6 & 1.4 & 9.0 & 5.8 & 3.8 & 2.2 \\
\hline $\mathrm{P}_{\text {macro }}, \mathrm{kW}$ & 0.80 & 0.67 & 0.56 & 0.49 & 2.7 & 1.7 & 1.1 & 0.64 \\
\hline $\mathrm{P}_{\mathrm{av}}, \mathrm{mW}$ & 30 & 42 & 38 & 34 & 152 & 120 & 79 & 38 \\
\hline
\end{tabular}
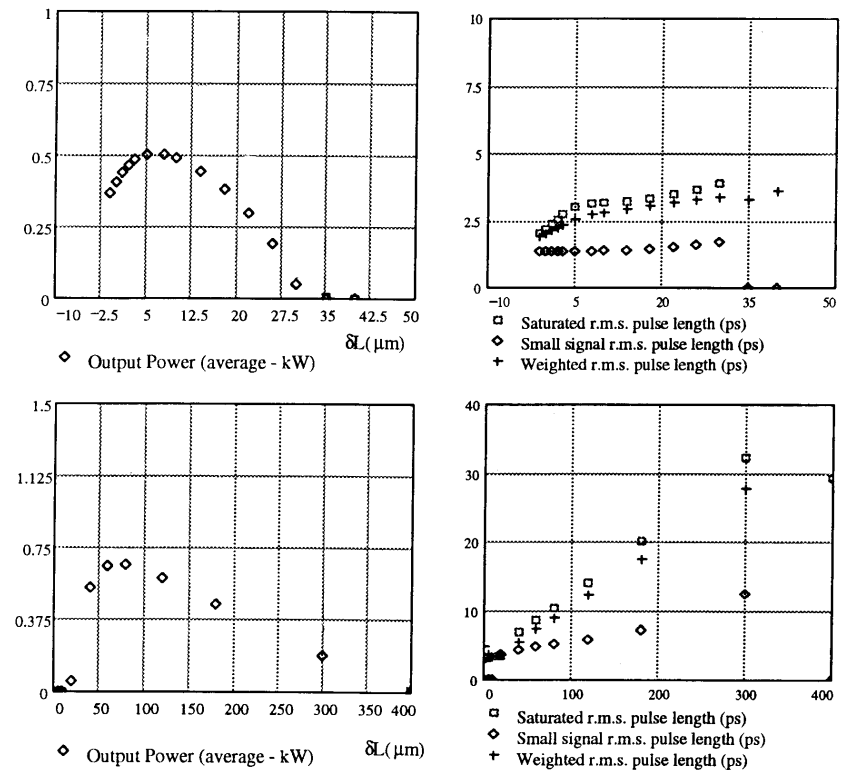

Fig. 5 Results of pulse propagation analysis (see text).

A more accurate numerical analysis of pulse propagation effects has been made, using a code developed by the ENEA group based on the solution of the FEL integral equation including saturation effects. Figure 5 shows the output power averaged over the macropulse and the optical pulse length, near the beginning of the macropulse (small signal value) and at the end (saturated value), as a function of cavity length detuning $(\delta \mathrm{L})$ for 2 cases : FEL-1 at $16 \mu \mathrm{m}$ (upper) and FEL-2 at $250 \mu \mathrm{m}$ (lower). In general the results confirm that saturation is reached in the $5-250 \mu \mathrm{m}$ range, and that the pulse energy and power is in agreement with the previous calculations. It can also be seen that the pulse length at small detuning is smaller than the electron pulse length $(\mathrm{rms}=4.2$ ps), but increases with detuning and due to saturation, particularly in the case of large slippage (e.g. at $250 \mu \mathrm{m}$ ).

\section{PRESENT STATUS}

The work presented here is a summary of a more detailed Conceptual Design Report that has recently been completed. The present phase of activity concerns the identification of potential users and possible collaborators, as well as sources of funding. A formal collaborative agreement between the Italian partners is also being prepared.

\section{REFERENCES}

[1] C.J. Bocchetta et al., this Conference.

[2] M. Castellano et al., Proc. 3rd European Particle Accelerator Conference, Editions Frontières (1992) p. 611

[3] G. D'Auria et al., this Conference.

[4] F. Rosatelli et al., Proc. 1991 US Particle Accelerator Conference, p. 2760.

[5] M. Castellano et al., Nucl. Instr. Meth. A304 (1991) 204. 